\title{
Research on Promoting the Integration and Innovation of Culture and Technology
}

\author{
Yali Liang \\ College of Management \\ Shanghai University of Engineering Science \\ Shanghai, China \\ 592996003@qq.com
}

\begin{abstract}
By using the methods of literature research and case analysis; discusses the necessity of culture and technology of integration and innovation; from the theoretical point of view to analyze mainly several aspects of the integration development of culture and technology; constructs the mechanism model of the integration of culture and technology; sums up the opportunities of integration and innovation and puts forward some countermeasures and suggestions to promote the development of integration and innovation of culture and technology. The paper thinks, promoting the development of integration and innovation of culture and technology is conducive to enhance the overall level of cultural and creative industries, and promote the optimization and upgrading of the structure of cultural and creative industry, which is of great value and significance to the development of national economy.
\end{abstract}

Keywords—culture; technology; innovation; integration

\section{INTRODUCTION}

In recent years, more and more polymorphic industries have emerged in the world and different industries have begun to penetrate each other. The most frequent and obvious industries are the cultural and technological industries. The areas and degrees of their integration are also becoming more extensive and in-depth. The organic integration of cultural soft power and technological hard power has promoted the rapid development of economy and society. However, compared with developed countries, China's cultural and technological industries have not yet full of organic integration, the promoting role of culture in technology and the supporting role of technology have not yet played out ${ }^{[1]}$. By clarifying the relationship between culture and technology, this paper studies the current situation of the integration development of culture and technology in our country, discusses the problems existing in the integration development of culture and technology, and puts forward the countermeasures and suggestions on promoting the integration and innovation of culture and technology, which not only enriches and develops the theories of industry economics, but also for China's construction of an international cultural metropolis to provide theoretical guidance and decision-making reference, which has good theoretical and practical value ${ }^{[2]}$.

\section{The INTEGRATES ThEORETICAL BASIS OF CULTURE AND TECHNOLOGY}

The integration of culture and technology is mainly reflected in resources, enterprises and industries. Therefore, this article will be from the industrial field level, the enterprise level and the resource element level to analyze the connotation of the integration. (1) From the perspective of industry, the integration of culture and technology means that technologybased enterprises should shift existing products and technologies to cultural industries, grasp the inherent needs of the development of cities, regions and even national cultural industries, and explore the new technologies and products to promote the development of cultural industries. (2) From the aspect of enterprise main body, the integration of culture and science and technology can be interpreted as the cooperation between various kinds of situations between cultural enterprises and science and technology enterprises, to realize the penetration of the intrinsic demand of product innovation of cultural enterprises into the technological innovation field of science and technology enterprises, or the integrated application of innovative products of science and technology enterprises into cultural products.(3) From the perspective of resource elements, the culture is regarded as a cultural and creative resource. In the process of product innovation, science and technology enterprises dig deep into the cultural resources of their cities, regions and even countries and put forward exquisite cultural ideas. By means of scientific and technological innovations, they transform cultural ideas from invisible minds into cultural science and technology products or technology ${ }^{[3]}$.

Culture and technology interact with each other. However, the integration of they is not only facilitated by both sides, but also requires more factors to work together. The integration of culture and technology is not only the purpose, but also the means. The resultant superposition effect makes the cultural products and their derivatives can create more value than before.

The Young Scholars Research Fund Project of Shanghai Association of Productivity Science "Research on promoting the integration and innovation of Shanghai culture and technology" (QN_2017003);The Graduate Student Research And Innovation Projects of Shanghai University of Engineering Science "Research on promoting the integration and innovation of Shanghai culture and technology"(E3-0903-17-01185,17KY0353) 


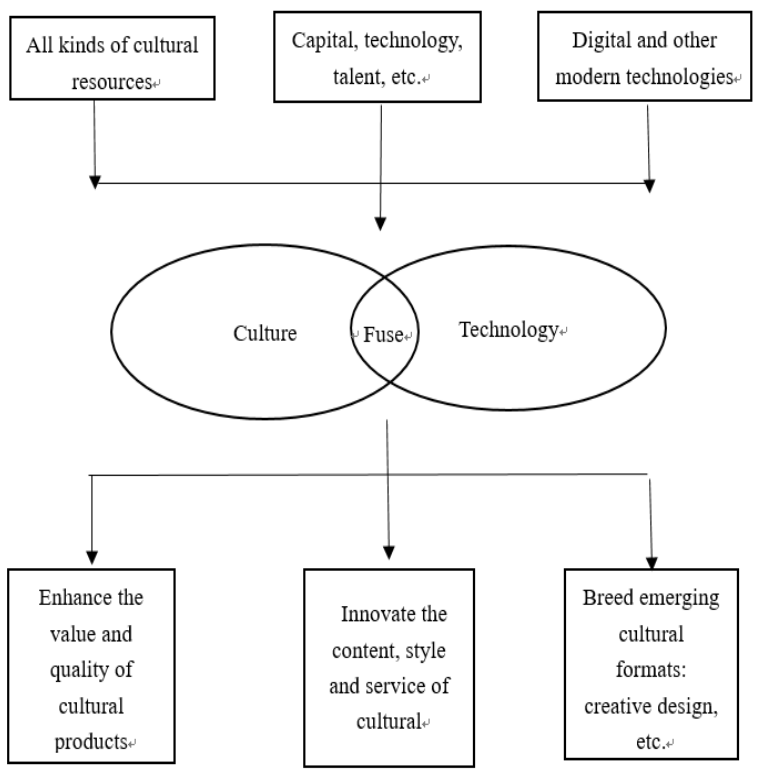

Fig.1. Fusion mechanism of culture and technology

\section{THE INTEGRATION DEVELOPMENT STATUS}

\section{A. The ability of market resources allocation is effectively enhanced}

Investment and financing, mergers and acquisitions in the cultural industry continue to heat up, which makes funds fully protected. In 2016, in the context of ' capital winter ', culture, sports and entertainment has become the new trend of capital chasing and the investment in merger has not diminished ${ }^{[4]}$. Since the end of 2015, the DianPing on the merger with the MeiTuan and the acquisition of Guevara and the WePiao, industry mergers and resources of cross-border integration are more active.

\section{$B$. The emerging industry hot spots are frequent}

Digital publishing continues to dominate. The annual output value of the digital publishing industry in Shanghai is expected to exceed 75 billion Yuan, an increase of 14\% over the previous year, of which the online literature market share of more than $70 \%$. According to the digital publication of "CiHai" (Seventh Edition), the digital publishing platform of "CiHai" will be co-ordinated. The 2016 Shanghai Press and Publication set up Special Funds (digital publishing field) for funding the "CiHai" underlying database project about one million Yuan ${ }^{[5]}$. Network audio should actively strengthen and dock traditional publishing industry, the audio sharing platform ---Himalaya FM United many well-known publishing group jointly held the '2016 China audio publishing industry launch conference and collective signing ceremony'.

\section{The integration effectiveness of culture and technology is showing}

Focusing on the overall goal of "building a science and technology innovation center with global influence", Shanghai focuses on 'new technologies, new industries, new models and new formats' and earnestly grasps the key technological links in the field of culture and technology. In the field of $4 \mathrm{~K}$ ultra
HDTV, seven special working groups including Shanghai Media Group, Shanghai Jiao tong University, National Center for Digital TV Engineering and Orient Cable set up a special working group to carry out industrial technology research and standard-setting together with CCTV and other agencies.

\section{The Problems in the INTEgration DeVelopment of CULTURE AND TECHNOLOGY}

\section{A. The integration lacks consciousness}

The fusion between the culture and technology is lack of consciousness and initiative, and there are some difficulties in integration process with no direction. Shanghai's current industrial scale is generally small and scattered, which makes it difficult to form a spillover effect that can take the initiative to guide the deep integration of science and technology enterprises and cultural enterprises. From the perspective of the added value of various cultural and creative industries in Shanghai, there is a phenomenon that "walking is the key but not performing well". The definition of cultural and creative industries that various departments should focus on nurturing and supporting is still blurry and lacks a relative unified, authoritative industry-oriented benchmark ${ }^{[6]}$.

\section{B. The scarcity of high-end talent in cross border integration of culture and technology}

The integration of culture and technology requires compound talents. With the deepening of integration of culture and technology, the shortage of high-end compound talents who master high-tech and are familiar with the law of cultural development has become an increasingly important issue and short board that constrain the rapid development of integration of culture and technology. The division of labor in modern industries is getting more and more elaborate, the gap between industries is gradually deepening, and the distance between various professions is further and further. Experts in the fields are interpenetrating each other and learning from each other's fields is insufficient. Blending with each other is difficult. And there are structural contradictions in personnel training. Most colleges also tend to ignore the arts and technologies and neglect the integration of arts and sciences in teaching staff construction, teaching facilities and equipment construction, teaching methods and teaching research topics ${ }^{[7]}$.

\section{There is little intersection in innovation results of culture and technology}

Scientific and technological innovation is the driving force behind the development of cultural industries. Science and technology provide technical support for the development of cultural industries, enabling the elements of cultural production to be optimally combined in the process of innovation and expanding the space for industrial development. Although Shanghai is a pioneer city in the field of cultural and creative development, the existing integration of culture and technology is not enough to innovate. There is no qualitative breakthrough in philosophy and no sustained creativity can be formed. The deep integration of culture and technology requires a large number of innovative subjects as well as a social organic system of government, enterprises and schools 
that provide services for the integration of culture and technology. However, at present, Shanghai still lacks a complete system of research, development, production, management and support for the "seamless connection" between scientific achievements and cultural and creative achievements. Their strength is weak and it is difficult to make them bigger and stronger. Another point is that the protection of intellectual property is not enough. Intellectual property is the key to the deep integration of culture and technology ${ }^{[8]}$.

\section{The lack of interaction space between culture and technology}

From the industrial mechanism analysis, the lack of concentration of industrial scale and spatial distribution, it will be difficult to form spillover effect for promoting the effective matching of culture and technology. The cultural and creative industries in the spatial distribution have obvious spatial agglomeration effect in Beijing and Shenzhen. For example, Beijing owns a number of professional service platforms such as film, animation and digital publishing, and initially formed Haidian --- digital content, Shijingshan --- anime games, Dongcheng --- artwork trade, Xicheng --- design creativity and Chaoyang---industrial clusters with distinctive characteristics of culture and media, especially Haidian District, account for almost half of the development of Beijing's cultural industries. A large number of industrial projects, financial institutions and human resources converge in such iconic areas as Zhongguancun, making it easy for the integration of culture and technology has brought a positive spillover effect. Industrial development orientation and spatial dislocation make it difficult for culture and technology to achieve a "coupling" in space of service, demand and information ${ }^{[9]}$.

\section{E. Many supporting policies are difficult to share}

The innovation fusion of culture and technological ultimately requires a series of innovative breakthroughs in the policy environment, institutional mechanisms, and even major changes. From the actual situation of the latest cultural and creative industrial policies in major cities in China, Shanghai does not have a clear lead. There is also a lack of effective transmission mechanism between the microscopic subject and the macro-orientation in the integration of culture and technology. Take Pudong New Area comprehensive reform pilot project as an example. The key tasks of the third round of three-year plan of action are still mainly focused on five aspects: Lujiazui Financial City, Comprehensive Bonded Zone, innovation-driven (optimizing human resources service system), urban-rural overall planning and government management. The innovation and convergence of culture and technology in financial mechanism and policy innovation has not received the full attention. Such dislocation of industry and policy guidance also leads to the limitation of the function platform development of Shanghai Cultural Property Exchange, Shanghai Copyright Exchange Center and Shanghai Cultural and Creative Industries Investment and Financing Service Platform.

\section{THE OPPORTUNITIES FOR THE INTEGRATION PF CULTURE AND TECHNOLOGY}

\section{A. Adhering to the integration orientation of culture and technology}

Integration of culture and technology is one of the important ways to transform the mode of economic development. The report of the 18th CPC National Congress explicitly proposed that the integration of culture and technology should be promoted and to the national strategic level. On this basis, Shanghai Municipal Party Committee and Shanghai Municipal Government have actively participated in this project, which has led Zhangjiang High-tech Park to become one of the first 16 national demonstration bases for integration of culture and technology and combined Shanghai's actual support and guidance for the development of Shanghai's cultural, science and technology integration industry. National strategic guidance and local government policy support require that Shanghai actively integrate its national development strategies such as the 'Belt and Road,' the Yangtze River Economic Zone and the Free Trade Zone ,and continue to push forward supply-side structural reforms in the cultural field and firmly grasp the opportunities of building a scientific and technological innovation center with global influence for provide an opportunity for the integration development of Shanghai culture and technology industries.

\section{B. Conform to the trend of industrial development}

The economic crisis is an opportunity for culture and technology industries. The culture and technology integration industry has the characteristics of anti-economic cycle. The United States, Britain, Japan and South Korea all started their efforts to develop a culture-science integration industry during the economic recession so as to achieve the postindustrialization transition to a service-oriented and high value-added manufacturing industry and promote economic restructuring and upgrading. At present, the integration of culture and technology has become a pillar industry in the western developed countries, and its output value is generally above $10 \%$ of GDP. Therefore, under the post-financial crisis era and the third industrial revolution, on the basis of grasping the industrial development trend in developed countries, promoted the integration of culture and technology, enhanced innovation capability and enhanced its comprehensive international competitiveness.

\section{To seize the domestic and international consumer market}

No matter from the regional, national or international backgrounds, people's consumption structure gradually shifts from material consumption to cultural consumption and spiritual consumption, from living-type consumption to enjoyment-based consumption that pursues quality of life. At the same time, the development of integration not only can obtain a large amount of economic profits, but also can integrate its own cultural ideology into the material products and output its own spiritual civilization while outputting its own material civilization so as to affect the production and consumption of the audience habits and ideology, and enhance 
the recognition of the nation's culture by all countries in the world and gain more access to the international market.

\section{COUNTERMEASURES AND SUGGESTIONS}

In summary, this article proposes some countermeasures and suggestions mainly from the aspects of coordination mechanism, fiscal policy, capital investment, intellectual property protection.

\section{A. To establish an integration cooperation mechanism}

The government should establish a joint conference system about the integration of culture and technology with relevant government departments. Joint meeting is responsible for coordination, decision-making deployment of major planning and major projects of culture and technology integration development. Give full play to the role of the cooperation mechanism between municipal departments and municipalities, closely match with the strategy of national cultural and scientific innovation, and strive for the establishment of national cultural and scientific innovation projects. Improve the urban linkage mechanism to guide all districts and counties to integrate advantages of resources, the development of characteristic cultural and technology integration industries cluster.

\section{B. Fulfill fiscal and taxation policies for the integration of culture and technology}

Earnestly implement the pre-tax deduction policy of corporate R \& D expenses, and actively promote preferential tax policies for cultural and technology enterprises to make full use of the pilot reform of "reforming the business camps and increasing the number of employees in the municipality". Strive for the export tax rebate policy of cultural technology products and services, and promote the "going global" of cultural and technological products and technical services. Take full advantage of the demonstration base in finance and tax support, science finance and other aspects of the first opportunity to take the lead in the integration of innovation and technology to integrate science and technology to improve.

\section{Increase the investment in the integration development of culture and technology}

Increase the city's special funds for science and technology projects, cultural special funds and other financial capital revenue, encourage and support cultural and technological enterprises to carry out the application of key technologies and cultural equipment development. Encourage and support public technology service platforms to construct and optimize in integrating development's key areas of culture and technology and innovate the ways of investment for supporting the enhancement of enterprise's innovation level, through the purchase of government in services, project subsidies, subsidies for public services, awards and subsidies, etc.

\section{Strengthen the financial capital support of the integration development}

We will encourage all kinds of financial institutions to increase their product innovation. In the face of culture, technology and other light-asset culture enterprises, we will provide targeted investment and financing and guarantee support, and actively guide the financial support for science and technology policies toward the culture and technology enterprises. We will actively promote multi-channel direct financing of cultural and creative industries, and encourage cultural and technology enterprises to enter into listed transactions in the equity custody trading center. We will strengthen and improve the insurance services for the export of cultural technology enterprises, projects and products that are mainly supported by the state and this Municipality.

\section{E. Strengthen the protection and management of intellectual property in the field of culture and technology.}

Improve the intellectual property evaluation system of integration key areas of culture and technology in digital publishing, animation games, network audio-visual, creative design and others, and establish and improve the intellectual property credit guarantee mechanism. Encourage the achievement of independent innovation of cultural and technological enterprises to apply, register and register intellectual property rights in time. Establish digital copyright registration center to encourage cultural and technological enterprises to register copyright. Actively create the environment of protecting intellectual property rights, and increase intellectual property protection and law enforcement of illegal and illegal activities.

\section{CONCLUSION}

In conclusion, promoting the development of integration and innovation of culture and technology is conducive to enhance the overall level of cultural and creative industries, and promote the optimization and upgrading of the structure of cultural and creative industry, which is of great value and significance to the development of national economy.

\section{REFERENCES}

[1] Hu Jinjun. Reflections on Promoting the Integration of Shanghai Culture and Science and Technology [J] .Shanghai Cultures, 2013 (2x): 80-87.

[2] CUI Mu-hua. Integration of Culture and Science and Technology: Connotation, Mechanism, Mode and Approach [J] .Science Management Research,33 (1): 36-41.

[3] Shanghai Annual Report on Promoting the Integration of Culture and Science and Technology in 2013. Shanghai Science and Technology, 2013-10-28.

[4] 2013 Shanghai Cultural and Creative Industries Development Report. Shanghai Economic Commission, 2013-06-27.

[5] Zhao Qingyi. Promoting cultural and creative industries to become pillar industries. Shanghai Modern Service Federation, 2012-06-29.

[6] Han Yushu. The Integration of Culture and Science and Technology: A Study on Connotation, Mechanism, Model and Route [J] .Science Management Research, 2015 (5): 21-24.

[7] Zhou Luming. Establishing a Coordination Mechanism between Modern Science and Technology and Chinese Culture [J] .Science \& Technology Progress and Policy, 1989,5 (3): 46-48.

[8] Lu Naiji. Technology to promote the role of culture [J]. Science and Technology and Dialectics, 1995,12 (6): 48-52.

[9] Liu Li, Yang Decai. Science and Technology Progress and Development of Advanced Culture [J]. Socialism Research, 2004,28 (2): 20-22. 